\title{
Reversing Cocaine-Induced Plasticity with Zeta Inhibitory Peptide
}

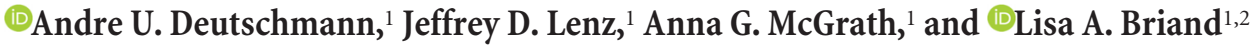 \\ ${ }^{1}$ Department of Psychology, and ${ }^{2}$ Neuroscience Program, Temple University, Philadelphia, Pennsylvania 19122
}

Cocaine-induced plasticity persists during abstinence and is thought to underlie cue-evoked craving. Reversing this plasticity could provide an opportunity for therapeutic intervention. Converging evidence suggest that zeta inhibitory peptide (ZIP) eliminates memories for experience-dependent behaviors, including conditioned drug associations. However, the effect of ZIP on reward seeking and druginduced plasticity is unknown. The current study examined the effect of ZIP administration in the nucleus accumbens on reinstatement (RI) of cocaine seeking, a rodent model of relapse. We demonstrate that intra-accumbal ZIP administration blocks cocaine-primed RI in rats when administered $24 \mathrm{~h}$ or 1 week before testing. These effects of ZIP on drug seeking are specific, as we did not see any effect of ZIP on RI of sucrose seeking. ZIP is a synthetic compound designed to inhibit the atypical PKC, PKM $\zeta$, a protein implicated in learning and memory. However, recent evidence from PKM $\zeta$-knock-out (KO) mice suggests that ZIP may function through alternative mechanisms. In support of this, we found that ZIP was able to block cue-induced RI in PKM $\zeta$-KO mice. One possible mechanism underlying addictive phenotypes is the ability of cocaine to block further plasticity. We hypothesized that ZIP may be working to reverse this anaplasticity. Although ZIP has no effect on accumbal LTD in slices from naive or yoked saline mice, it is able to restore both NMDA-dependent and mGluR5-dependent LTD in animals after cocaine self-administration and withdrawal. These findings demonstrate that intra-accumbal ZIP persistently reverses cocaine-induced behavioral and synaptic plasticity in male and female rodents.

Key words: cocaine; LTD; mGluR; NMDAR; reinstatement; zeta-inhibitory peptide

\section{Significance Statement}

Zeta-inhibitory peptide (ZIP) has been shown to disrupt memory maintenance for experience-dependent behaviors. We examined the effect of ZIP infused into the nucleus accumbens on the reinstatement (RI) of cocaine seeking. We found that intra-accumbal ZIP blocked RI of cocaine seeking $24 \mathrm{~h}$ and 1 week later. This effect was specific to RI of cocaine seeking as ZIP did not disrupt RI of food seeking. In conjunction with these behavioral studies we examined the ability of ZIP to reverse cocaine-induced deficits in LTD. We found that ZIP was able to rescue two forms of LTD in cocaine-experienced mice. These studies demonstrate that ZIP is able to reverse cocaine-induced behavioral and synaptic plasticity in a persistent manner.

\section{Introduction}

Cocaine addiction is a chronic, relapsing disorder characterized by continued use in the face of adverse consequences. Despite decades of research, a safe, efficacious pharmacological treatment for cocaine addiction remains to be discovered. Relapse to cocaine use is partially mediated by persistent cue-driven, drug

Received June 12, 2019; revised July 18, 2019; accepted Aug. 7, 2019.

Author contributions: A.U.D. and L.A.B. designed research; A.U.D., J.D.L., A.G.M., and L.A.B. performed research; A.U.D., J.D.L., and L.A.B. analyzed data; A.U.D. wrote the first draft of the paper; A.U.D., A.G.M., and L.A.B. edited the paper; L.A.B. wrote the paper.

This work was supported by the National Institute on Drug Abuse (Grants \#DA033372 and \#DA047265 to L.A.B.) and the Deutsche Forschungsgemeinschaft (Grant \#DE 2828/1-1 to A.U.D). We thank Richard L. Huganir for providing the initial breeders for the PKM $\zeta$-KO mouse studies.

The authors declare no competing financial interests.

Correspondence should be addressed to Lisa A. Briand at Ibriand@temple.edu.

https://doi.org/10.1523/JNEUROSCl.1367-19.2019

Copyright $\odot 2019$ the authors memories (Childress et al., 1993; Dackis and O'Brien, 2001). These memories for drug-paired cues elicit craving in human addicts and reinstate extinguished cocaine-seeking behavior in rodent models (Everitt et al., 2018). During abstinence memories associated with drug-taking persist and the inability to eliminate these drug memories is thought to underlie addiction. Although many studies have demonstrated temporary pharmacological inhibition of cue-driven cocaine seeking (Cornish et al., 1999; Mahler et al., 2013, 2014; Knackstedt et al., 2014; Reissner et al., 2015; LaCrosse et al., 2017; Manuszak et al., 2018), a more persistent disruption has been elusive.

Zeta-inhibitory peptide (ZIP) is a cell-penetrating peptide derived from the pseudosubstrate domain of the PKC isoform, $\mathrm{PKM} \zeta$, a constitutively active splice variant of PKC $\zeta$ (Pastalkova et al., 2006). This peptide has been used extensively in memory studies to support a role for $\mathrm{PKM} \zeta$ in maintaining memories via long-term potentiation (Hrabetova and Sacktor, 1996; Past- 
alkova et al., 2006; Sacktor, 2011; Zhang et al., 2016). Additionally, ZIP has also been shown to disrupt cocaine-conditioned reward in the nucleus accumbens (NAc) (Li et al., 2011; Shabashov et al., 2012), cocaine-induced synaptic potentiation in the ventral tegmental area (VTA) (Ho et al., 2012; Vaquer-Alicea et al., 2018), and cocaine sensitization when injected into the ventricle (Howell et al., 2014). However, recent studies using mice deficient in $\mathrm{PKM} \zeta$ show that these isoforms are not necessary for synaptic plasticity or memory (Lee et al., 2013; Volk et al., 2013). ZIP is still able to impair LTP maintenance and several types of memory, including conditioned drug associations, in mice deficient in PKC $\zeta / \mathrm{PKM} \zeta$, suggesting that the actions of ZIP are independent of PKM $\zeta$ (Lee et al., 2013).

Here, we examined the ability of ZIP to alter cocaine-induced behavioral and synaptic plasticity. To do this, we examined the ability of intra-accumbal ZIP administration to disrupt reinstatement (RI) of cocaine seeking in both rats and mice. Synaptic plasticity within the NAc is associated with cue driven cocaine seeking. Specifically, cocaine self-administration leads to blunted long-term depression (LTD), a form of meta plasticity that is thought to underlie reduced behavioral flexibility in individuals with substance use disorder (Martin et al., 2006; Moussawi et al., 2009; Kasanetz et al., 2010). To determine whether ZIP is able to rescue this blunted plasticity after cocaine use, we examined the effect of ZIP on LTD in the NAc after cocaine self-administration. Our results suggest that ZIP is able to disrupt cocaine-induced behavioral and synaptic plasticity in a persistent manner.

\section{Materials and Methods}

Subjects. Male Sprague Dawley rats (Rattus norvegicus) weighing 250$275 \mathrm{~g}$ were obtained from Taconic Laboratories. Animals were individually housed with food and water available ad libitum in their home cages. Male and female heterozygous PKM $\zeta$-knock-out (KO) mice on a C57BL/6 background (as described previously in Volk et al., 2013) were mated resulting in mutant and wild-type littermates. Additional male and female C57BL/6J mice were bred in house for electrophysiology experiments. Mice (2-6 months old, 20-40 g; age matched across group) were group housed until the start of the behavioral experiments at which point they were individually housed. All animals were housed in a temperature- and humidity-controlled animal care facility with a $12 \mathrm{~h}$ light/dark cycle (lights on at 7:00 A.M.). All procedures were approved by the Temple University Animal Care and Use Committee.

Drugs. Cocaine was obtained from the National Institutes of Drug Abuse Drug Supply Program (Bethesda, MD) and dissolved in sterile $0.9 \%$ saline. ZIP (catalog \#2549) and a scrambled, inactive form of the peptide (Serrano et al., 2008), SCR-ZIP (catalog \#3215), were obtained from Tocris Bioscience. For the in vivo drug administration, ZIP and SCR-ZIP was dissolved in artificial CSF (ACSF). For the electrophysiological recordings, a stock solution was made by dissolving ZIP in $80 \%$ $\mathrm{H}_{2} \mathrm{O}$ and $20 \% \mathrm{ETOH}$. The final concentration of ETOH in the bath was $0.19 \%$.

Surgery. Rats and mice were anesthetized with $80 \mathrm{mg} / \mathrm{kg}$ ketamine and $12 \mathrm{mg} / \mathrm{kg}$ xylazine. An indwelling SILASTIC catheter was placed into the right jugular vein and sutured in place. Then the catheter was threaded subcutaneously over the shoulder blade and was routed to a mesh back mount platform (Strategic Applications) that secured the placement. The catheters were flushed daily with $0.1 \mathrm{ml}$ of antibiotic (Timentin, 0.93 $\mathrm{mg} / \mathrm{ml}$ ) dissolved in heparinized saline. The catheters were sealed with plastic obturators when not in use. After catheter insertion, rats and mice were immediately mounted in a stereotaxic apparatus (Kopf Instruments). Guide cannulas (rat: $14 \mathrm{~mm}, 24$ gauge; mouse; $9 \mathrm{~mm}$, 26 gauge) for microinjections were implanted bilaterally $2 \mathrm{~mm}$ (rat) or $1 \mathrm{~mm}$ (mouse) dorsal to the accumbens. Guide cannulas were cemented in place by affixing dental acrylic to stainless steel screws secured in the skull. The coordinates for the ventral ends of the guide cannulas, relative to bregma, were as follows: Rat: $1.2 \mathrm{~mm} \mathrm{~A} / \mathrm{P}, \pm 1.0 \mathrm{~mm} \mathrm{M} / \mathrm{L}$, and $5.2 \mathrm{~mm}$
$\mathrm{D} / \mathrm{V}$; mouse: $+1.5 \mathrm{~A} / \mathrm{P},+/-1.0 \mathrm{M} / \mathrm{L},-4.0 \mathrm{D} / \mathrm{V}$. An obturator $(14 \mathrm{~mm}$ (rat), $9 \mathrm{~mm}$ (mouse), 33 gauge) was inserted into each guide cannula to prevent occlusion.

Rat cocaine and sucrose self-administration, extinction and RI of cocaine seeking. After surgery, rats were allowed $7 \mathrm{~d}$ to recover before behavioral testing commenced. Initially, rats were placed in operant chambers and allowed to lever press for intravenous infusions of cocaine $(0.25 \mathrm{mg}$ of cocaine $/ 59 \mu$ l of saline, infused over a 5 s period) on a fixed-ratio 1 (FR1) schedule of reinforcement. When a cocaine infusion was delivered, a cue light above the active wheel was illuminated for $5 \mathrm{~s}$ and the house light turned off. Each operant session began with the intravenous administration of $0.25 \mathrm{mg}$ of cocaine (dissolved in $59 \mu \mathrm{l}$ of saline) to fill the catheter. Rats were allowed to self-administer a maximum of 30 injections per 120 min operant session. Once an animal achieved at least 20 infusions of cocaine in a single daily operant session under the FR1 schedule, the subject was switched to an FR5 schedule of reinforcement. The maximum number of injections was again limited to 30 per daily selfadministration session under the FR5 schedule. For both FR1 and FR5 schedules, a $20 \mathrm{~s}$ time-out period followed each cocaine infusion, during which time the house light remained off, active lever responses were tabulated but had no scheduled consequences. Responses made on the inactive lever, which had no scheduled consequences, were also recorded during both the FR 1 and FR 5 training sessions. After $18 \mathrm{~d}$ of daily cocaine self-administration sessions, drug seeking behavior was extinguished by replacing the cocaine with $0.9 \%$ saline. Daily extinction sessions continued until responding on the active lever was $<15 \%$ of the total active lever responses completed on the last day of cocaine self-administration maintained on a FR5 schedule of reinforcement. Typically, it took $\sim 7 \mathrm{~d}$ for rats to meet this criterion. Once cocaine self-administration was extinguished, animals entered the RI phase of the experiment. To control for any natural variation in RI behavior, all animals underwent a RI pretest in which a systemic priming injection of cocaine $(10 \mathrm{mg} / \mathrm{kg}$, i.p. $)$ was administered immediately before the test session. During the RI test sessions, satisfaction of the response requirement (i.e., five presses on the active lever) resulted in an infusion of saline rather than cocaine. Rats then underwent $1-2 \mathrm{~d}$ of extinction to return to the extinction criterion. Two hours after the final extinction session, rats received bilateral intraaccumbal microinfusions of ZIP $(30 \mathrm{nmol})$ or SCR-ZIP. They then received another cocaine-primed RI session either $24 \mathrm{~h}$ or 1 week later. Groups were balanced based upon their cocaine self-administration, extinction and RI data. Catheter patency was checked at the end of the cocaine self-administration phase and any animals that were no longer patent were removed from the study $(n=2)$.

Rat sucrose self-administration, extinction, and RI of sucrose seeking. A separate group of rats underwent a similar procedure with $18 \mathrm{~d}$ of sucrose self-administration (FR1 transitioning to FR5 as described above), extinction of sucrose seeking, and sucrose-primed RI. For the sucrose RI, the experimenter remotely administered one sucrose pellet every 2 min for the first $10 \mathrm{~min}$ of the RI test session. During this session, active lever presses had no scheduled consequences. Rats were only tested for sucrose $\mathrm{RI}$ at the $24 \mathrm{~h}$ postmicroinfusion time point.

Mouse food training, cocaine self-administration, extinction, and RI. Before catheterization, mice were trained to perform an operant response for sucrose pellets. The mice were placed in operant chambers (Med Associates) where they learned to spin a wheel manipulandum to receive the sucrose pellet. When the pellet was delivered, a cue light above the active wheel was illuminated, a $2900 \mathrm{~Hz}$ tone played, and the house light turned off. This was followed by an $8 \mathrm{~s}$ time-out where the house light remained off and spinning the wheel had no programed consequences. Mice were able to self-administer up to 50 pellets per $60 \mathrm{~min}$ operant session. The mice were food restricted to $\sim 90 \%$ of their free feeding weight throughout the course of the operant training. They were returned to ad libitum feeding $3 \mathrm{~d}$ into the cocaine self-administration sessions. After $10 \mathrm{~d}$ of food self-administration, mice underwent jugular catheterization surgery as described above. Mice were given 3-4 d to recover from surgery before resuming behavioral testing. The cocaine self-administration testing was measured over $2 \mathrm{~h}$ sessions ( $6 \mathrm{~d}$ per week) in the same chamber used for the operant food training. During testing, responding on the active wheel delivered an intravenous cocaine injec- 
tion $(0.6 \mathrm{mg} / \mathrm{kg} /$ infusion, $)$ paired with the same cues as the food training. After $10 \mathrm{~d}$ of cocaine self-administration, cocaine seeking was extinguished by replacing the cocaine with $0.9 \%$ saline. During extinction, the light and tone cues were not present. Daily $2 \mathrm{~h}$ extinction continued until the mice met the extinction criterion of $<25 \%$ of their responding during the self-administration (average of the last $3 \mathrm{~d}$ ). Two hours after the extinction session mice received microinjections of either ZIP or Scr-ZIP (see below for more details). Twenty-four hours after meeting the extinction criterion animals underwent a cue-induced RI session. The light and tone were presented noncontingently for $20 \mathrm{~s}$ every 2 min during the first $10 \mathrm{~min}$ of the session. For the remaining $110 \mathrm{~min}$, the cues were presented after responses on the active wheel, just as was done during the cocaine self-administration sessions. During RI, the mice received saline infusions after active responses. For the physiological measurements, mice were exposed to 10-12 d of cocaine self-administration or yoked saline experience. Saline-yoked mice were placed in identical operant chambers however their responding had no programmed consequences. Instead, they received saline infusions along with cue presentations when their partner mouse received cocaine. Mice were killed 10-14 $\mathrm{d}$ after the final day of self-administration. As previous work has shown LTD to be disrupted in rodents both with and without extinction training (Moussawi et al., 2009; Briand et al., 2014), these mice were exposed to forced abstinence rather than active extinction.

Microinjection procedures. Obturators were removed from the guide cannulas and 33-gauge, $16 \mathrm{~mm}$ (rat) or $10 \mathrm{~mm}$ (mouse) stainless steel microinjectors were inserted. Bilateral infusions were performed simultaneously over $2 \mathrm{~min}$ in a total volume of $0.5 \mu \mathrm{l}$ (rat) or $0.4 \mu \mathrm{l}$ (mouse) per hemisphere. After infusion, microinjectors were left in place for an additional $1 \mathrm{~min}$ to allow for diffusion of the drug solution away from the tips of the microinjectors.

Verification of cannula placements. After completion of all microinjection experiments, rats were given an overdose of pentobarbital (100 mg/ $\mathrm{kg}$ ) and perfused with $0.9 \%$ saline followed by $10 \%$ formalin. Brains were removed and coronal sections $(100 \mathrm{~mm})$ were taken at the level of the NAc with a vibratome. The sections were mounted on gelatin-coated slides and stained with cresyl violet. An individual blind to behavioral responses confirmed cannula placements and removed any animals that had excessive cannula-induced damage. Two rats were removed from the studies due to inaccurate cannula placements and one was removed for excessive cannula-induced damage.

Nucleus accumbens slices. C57/B6J mice were decapitated after cervical dislocation. The brain was removed and coronal slices $(250 \mu \mathrm{m})$ containing the NAc were cut with a Vibratome (VT1000S, Leica Microsystems) in an ice-cold ACSF, in which $\mathrm{NaCl}$ was replaced by an equiosmolar concentration of sucrose. ACSF consisted of $130 \mathrm{~mm} \mathrm{NaCl}, 3 \mathrm{~mm} \mathrm{KCl}$, $1.25 \mathrm{~mm} \mathrm{NaH}_{2} \mathrm{PO}_{4}, 26 \mathrm{~mm} \mathrm{NaHCO}_{3}, 10 \mathrm{~mm}$ glucose, $1 \mathrm{~mm} \mathrm{MgCl}_{2}$, and 2 mM $\mathrm{CaCl}_{2}$ ( $\mathrm{pH} 7.2-7.4$ when saturated with $95 \% \mathrm{O}_{2} / 5 \% \mathrm{CO}_{2}$ ). Slices were incubated in ACSF at $32-34^{\circ} \mathrm{C}$ for $25 \mathrm{~min}$ and kept at $22-25^{\circ} \mathrm{C}$ thereafter, until transfer to the recording chamber. The osmolarity of all solutions was 300-315 mOsm. Slices were viewed using infrared differential interference contrast optics under an upright microscope (Slice Scope Pro; Scientifica) with a $40 \times$ water-immersion objective. For the ZIP bath manipulation ZIP $(5 \mu \mathrm{M})$ was added to the bath after $10 \mathrm{~min}$ of stable field EPSP (fEPSP) recording and another 10 min of EPSP recordings were taken to confirm the peptide did not alter baseline responding.

Electrophysiology. The recording chamber was continuously perfused (1-2 $\mathrm{ml} / \mathrm{min}$ ) with oxygenated ACSF heated to $32 \pm 1^{\circ} \mathrm{C}$ using an automatic temperature controller (Warner Instruments). Picrotoxin (100 $\mu \mathrm{M}$ ) was added to all solutions to block the $\mathrm{GABA}_{\mathrm{A}}$ receptor-mediated currents. Recording pipettes were pulled from borosilicate glass capillaries (World Precision Instruments) to a resistance of $4-7 \mathrm{M} \Omega$ when filled with the intracellular solution (whole-cell recordings) or to a resistance of 1-2 M $\Omega$ when filled with extracellular solution (field recordings). All recordings were conducted with a MultiClamp700B amplifier (Molecular Devices).

LTD. A bipolar tungsten stimulating electrode was placed within $100-$ $300 \mu \mathrm{m}$ from the recording electrode and used to stimulate excitatory afferents at $0.1 \mathrm{~Hz}$. The field recordings were performed within the core of the NAc. The amplitude of current pulses was set at the intensity required to evoke a $70 \%$ maximal response. After $10 \mathrm{~min}$ of stable responding, LTD was induced using a paired-pulse protocol (50 ms interpulse interval) consisting of a $1 \mathrm{~Hz}$ train of paired stimuli for $7.5 \mathrm{~min}$. Both the fEPSP slope amplitude were measured (graphs depict slope) from fEPSPs recorded at $0.1 \mathrm{~Hz}$ for $50 \mathrm{~min}$ following the pairing protocol. To induce mGluR5-dependent LTD, after recording a stable baseline for at least $10 \mathrm{~min}$ (S)-3,5-dihydroxyphenylglycine (DHPG; $100 \mu \mathrm{M}$ ) was applied via bath application for $10 \mathrm{~min}$, followed by ACSF. Field EPSPs were recorded for $60 \mathrm{~min}$ after the start of DHPG application. For the ZIP recordings, ZIP was present in the bath throughout the entire recording protocol.

Whole-cell recordings. Intracellular solution contained the following (in mM): $100 \mathrm{CsCH} 3 \mathrm{O} 3 \mathrm{~S}, 50 \mathrm{CsCl}, 3 \mathrm{KCl}, 0.2$ BAPTA, 10 HEPES, 1 $\mathrm{MgCl}$, 2.5 phosphocreatine-2Na, 2 Mg-ATP, 0.25 GTP-Tris, 1 QX-314 ( $\mathrm{pH}$ 7.2-7.3 with $\mathrm{CsOH}$, osmolarity 280-290 mOsm). Currents were low-pass filtered at $2 \mathrm{kHz}$ and digitized at $20 \mathrm{kHz}$ using a Digidata $1440 \mathrm{~A}$ acquisition board and pClamp10 software (both from Molecular Devices). Access resistance (10-30 M $\Omega$ ) was monitored throughout the recordings by injection of $10 \mathrm{mV}$ hyperpolarizing pulses and data were discarded if access resistance changed by $>25 \%$ over the course of data acquisition. Evoked responses were triggered by $100 \mu$ s constant-current pulses generated by an A310 Accupulser (World Precision Instruments) and delivered at $0.1 \mathrm{~Hz}$ via a bipolar tungsten stimulation electrode positioned within $100 \mu \mathrm{m}$ of the recorded cell. The amplitude of the current pulses was controlled by a stimulus isolator (World Precision Instruments Linear Stimulus Isolator A395) and was adjusted to elicit monosynaptic responses in the range of 100-300 pA (the required stimulus intensity ranged from 15 to $80 \mu \mathrm{A}$ ). AMPA/NMDA current ratios were computed by dividing the mean peak eEPSC at $-70 \mathrm{mV}$ (AMPAmediated) by the mean amplitude at $+40 \mathrm{mV}, 35 \mathrm{~ms}$ after the peak over a 2 ms window (NMDA-mediated). For all measures, cells from at least 3 animals, within each group, were used. Recordings were taken from cells within the accumbens core.

Data analysis. All analyses were performed using GraphPad Prism 7.0 software. Data were analyzed using two-tailed Student's $t$ test or two-way ANOVA with Sidak's post hoc test as appropriate. Statistical significance for all tests was set at $\alpha=0.05$.

\section{Results}

Intra-accumbal infusion of ZIP $24 \mathrm{~h}$ or 1 week before testing blocks cocaine-primed RI of cocaine seeking in rats

Rats underwent $18 \mathrm{~d}$ of cocaine self-administration followed by $7-10 \mathrm{~d}$ of extinction until reaching the extinction criterion $(<15 \%$ of their cocaine responding). Twenty-four hours after reaching the extinction criterion, all rats were given a cocaineprimed RI test in which they received an injection of cocaine (10 $\mathrm{mg} / \mathrm{kg}$, i.p.) immediately before being placed into the box under extinction conditions. Cocaine-primed RI was chosen because it induces the most robust RI in rats and allows for testing of multiple RI sessions without much decay in responding across tests. Rats in both groups exhibited a significant RI of cocaine seeking (Fig. 1A; two-way repeated-measures ANOVA (including all extinction 1, RI pretest, extinction 2, and RI posttest): main effect of test, $F_{(3,30)}=46.19, p<0.0001$; interaction, $F_{(3,30)}=10.0, p<$ 0.0001 , Sidak's post hoc test, SCR-ZIP and ZIP extinction vs pretest, $p<0.0001, n=6$ /group). Two hours after rats again reached the extinction criterion they were given a microinjection of either ZIP (30 nmol) or SCR-ZIP. Twenty-four hours after this peptide administration, rats were again tested on cocaine-primed RI. Rats that had received a microinfusion of ZIP into the accumbens failed to exhibit RI of cocaine seeking (Fig. 1A; Sidak's post hoc test, SCR-ZIP posttest vs ZIP posttest, $p<0.0001 ; n=6$ /group). To determine the longevity of ZIP's effects, an additional cohort of animals were injected with ZIP (30 nmol) or SCR-ZIP 1 week before the second cocaine-primed RI test. Although rats receiving the SCR-ZIP infusion exhibited RI of cocaine seeking after co- 
A

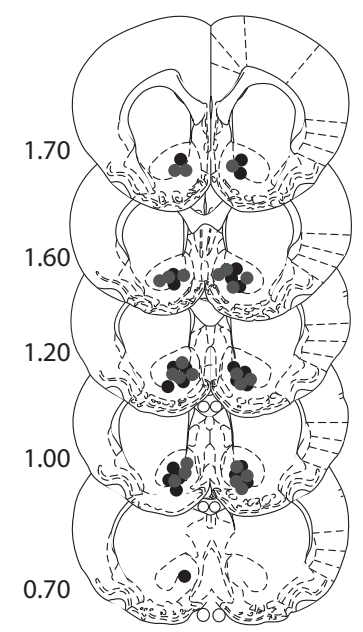

C

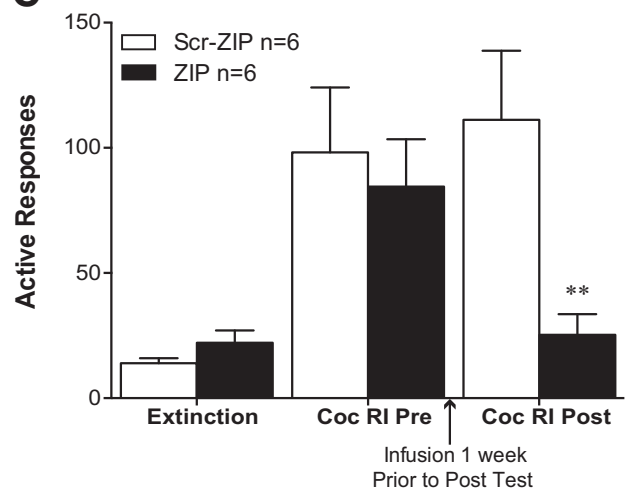

B

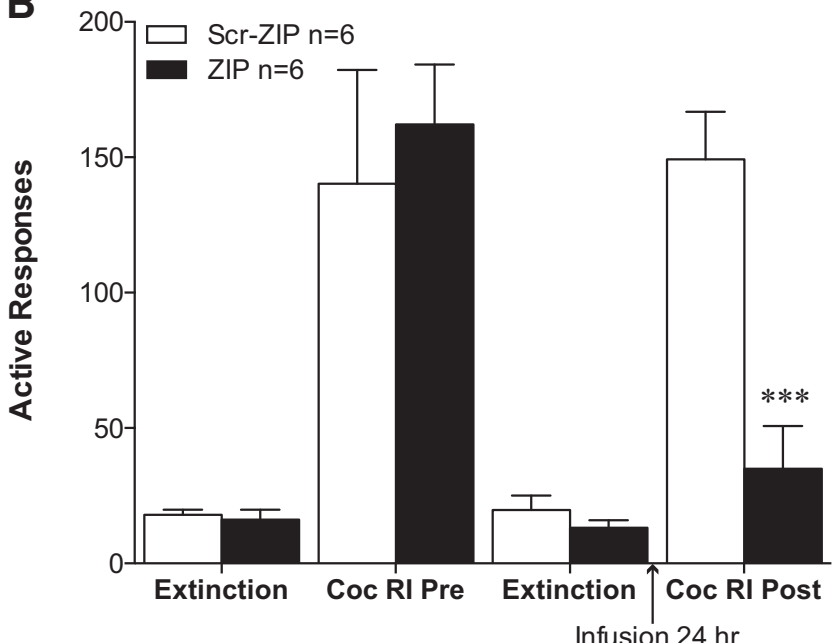

Infusion $24 \mathrm{hr}$

Prior to Post Test

D

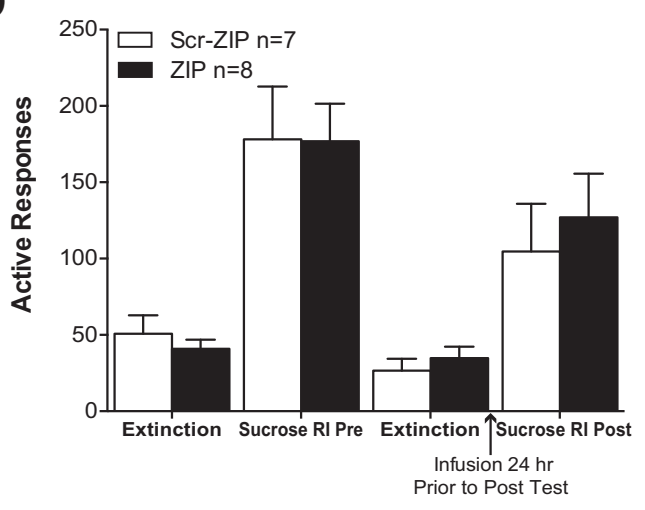

Figure 1. Intra-accumbal ZIP administration leads to persistent inhibition of cocaine seeking during RI. A, Dots indicate the location of the bilateral injections of $0.5 \mu$ l of ZIP (black) or Scr-ZIP (gray) into the nucleus accumbens. B, Despite both groups exhibiting equivalent levels of RI of cocaine (Coc) seeking during the pretest, intra-accumbal infusion of ZIP ( $30 \mathrm{nmol}$ ) $24 \mathrm{~h}$ before test blocked RI of cocaine seeking (bars represent mean \pm SEM; ${ }^{* * *} p<0.001$ Sidak post hoc ZIP vs SCR-ZIP on posttest, $n=6 /$ group). C, Similar blunted RI behavior was seen in rats that received intra-accumbal ZIP administration 1 week before the RI test $\left(C,{ }^{* *} p<0.01\right.$ Sidak posthoc ZIP vs SCR-ZIP on posttest, $n=6 /$ group). $D$, Intra-accumbal infusion of ZIP did not alter RI of sucrose seeking behavior $24 \mathrm{~h}$ after infusion ( $n=7-8 /$ group).

caine injection, rats that received intra-accumbal infusion of ZIP 1 week before the RI test did not (Fig. $1 B$; two-way repeatedmeasures ANOVA (including extinction, RI pretest, and RI posttest): main effect of test, $F_{(2,20)}=14.1, p=0002$; interaction, $F_{(2,20)}=6.3, p=0.008$; Sidak's post hoc test, SCR-ZIP posttest vs ZIP posttest, $p=0.0025 ; n=6$ /group).

Intra-accumbal infusion of ZIP $24 \mathrm{~h}$ before testing does not alter sucrose-primed RI of sucrose seeking in rats

To determine whether the effects of ZIP generalized to natural reinforcers, we ran a separate cohort of rats to test RI of sucrose seeking. After $18 \mathrm{~d}$ of sucrose self-administration and extinction, all rats were exposed to a sucrose-primed RI pretest to allow for appropriate balancing of the groups. Two hours after rats again reached the extinction criterion they were given a microinjection of either ZIP (30 nmol) or SCR-ZIP. Twenty-four hours after this peptide administration, rats were again tested on sucrose-primed RI. Both the animals that received ZIP and SCR-ZIP exhibited significant RI on the posttest (Fig. 1C; two-way repeatedmeasures ANOVA (including all extinction 1, RI pretest, extinction 2, and RI posttest): main effect of test, $F_{(3,39)}=31.9, p<$ 0.0001 ; interaction, $F_{(3,39)}=0.33, p=0.08$, Sidak's post hoc test, SCR-ZIP and ZIP extinction vs posttest, $p<0.0001 ; n=7-8$ / group).
Intra-accumbal infusion of ZIP $24 \mathrm{~h}$ before testing blocks cue-induced RI of cocaine seeking in PKM $\zeta-K O$ mice

For cross-species validation and to determine whether the effects of ZIP were dependent upon PKM $\zeta$, we examined the ability of ZIP to block RI of cocaine seeking in male and female wild-type and constitutive $\mathrm{PKM} \zeta$-KO mice. As the role of glutamatergic circuits is similar in different forms of RI (McFarland and Kalivas, 2001; Kalivas and McFarland, 2003; McFarland et al., 2004) and cues provide the most robust driver of RI behavior in mice, we chose to examine cueinduced cocaine seeking in these studies. Wild-type and constitutive $\mathrm{PKM} \zeta \mathrm{KO}$ mice underwent $10 \mathrm{~d}$ of food training to acquire operant responses for food, followed by $10 \mathrm{~d}$ of cocaine self-administration (FR1, $0.65 \mathrm{mg} / \mathrm{kg} /$ infusion) and an average of five extinction sessions. Mice were then divided into groups to normalize their cocaine intake, cocaine responding, and extinction responding. As described previously (McGrath et al., 2018), PKM $\zeta$ KO mice exhibit higher levels of responding during cocaine self-administration so the groups were balanced between infusion groups but not across genotype. Two-hours after their last extinction session mice were given microinfusions of either ZIP ( $30 \mathrm{nmol}$ ) or SCR-ZIP into their NAc. Twenty-four hours later they underwent a cueinduced RI session. Although mice given the SCR-ZIP infu- 
A Extinction Responding

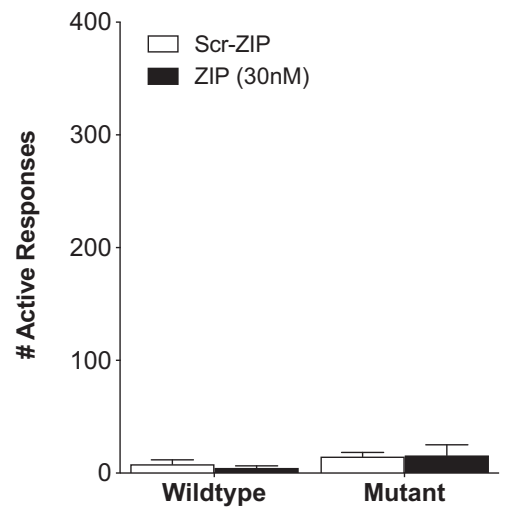

B Cue-Induced Reinstatement

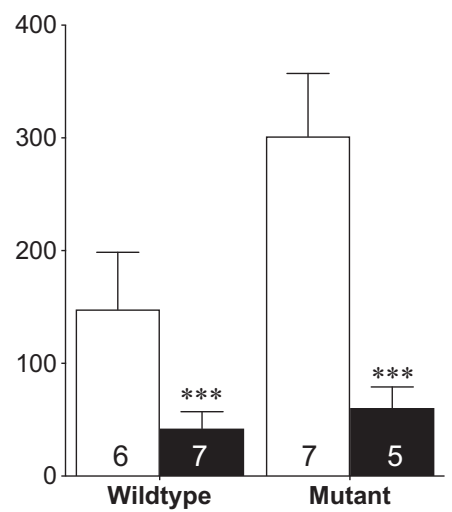

Figure 2. Intra-accumbal ZIP administration blocks cue-induced RI of cocaine seeking in constitutive PKM $\zeta-K 0$ mice. A, Two hours after meeting the extinction criteria, wild-type and PKM $\zeta$ KO mice received intra-accumbal infusions of either ZIP or SCR-ZIP. $B$, Twenty-four hours later, while both wild-type and PKM $\zeta$ KO mice that received SCR-ZIP infusions exhibited significant cueinduced RI of cocaine seeking, both groups that received ZIP infusions did not. Error bars indicate mean $\pm S E M$; ${ }^{* * *} p<0.001$ main effect of infusion on cue-induced RI. Numbers inside bars represent ns for each group.

ACSF vs cocaine ACSF, adjusted $p=$ $0.004 ; n=5-6$ slices (3-4 mice)/group; Fig. 4). Further, bath application of ZIP rescued DHPG-LTD in cocaine experienced mice (Sidak's multiple-comparisons test, cocaine ACSF vs cocaine ZIP, adjusted $p=0.009$; Fig. 4).

\section{Bath administration of ZIP does not disrupt evoked field potentials}

To confirm that ZIP did not disrupt the evoked field potentials, we examined responses during the $10 \mathrm{~min}$ before administration of ZIP and the 10 min after the start of bath application. We did not see any differences in average fEPSP slope (Control: $0.21 \pm 0.026$; ZIP: $0.20 \pm 0.024$; $n=8$ /group) or average fEPSP amplitude (control: $0.42 \pm 0.047$; ZIP: $0.43 \pm 0.056$; $n=8$ /group) during these two $10 \mathrm{~min}$ windows. sion exhibited significant RI of responding during the session, mice given the ZIP infusion did not (effect of test, $F_{(1,10)}=$ $16.76, p=0.002$; interaction, $F_{(1,10)}=9.54, p=0.01$; Sidak's multiple-comparisons test, SCR-ZIP vs ZIP RI test, adjusted $p=0.0009 ; n=5-7$ (group; Figure 2).

\section{Cocaine-induced disruption in NMDAR-dependent LTD is rescued by ZIP administration}

After demonstrating that ZIP blocks cocaine-induced behavioral plasticity, we next examined whether ZIP could reverse cocaineinduced synaptic plasticity in wild-type C57BL/6J mice. As blunted accumbal LTD is seen after cocaine experience (Martin et al., 2006; Moussawi et al., 2009; Kasanetz et al., 2010; Briand et al., 2014; Heinsbroek et al., 2017), we hypothesized that bath application of ZIP $(5 \mu \mathrm{M})$ would rescue this deficit. We found that slices from yoked control mice exhibited robust LTD within the NAc core (NAcc) and this response was not altered by bath application of ZIP (Fig. 3A). Consistent with what we have seen previously (Briand et al., 2014), LTD was absent in mice after $10-12 \mathrm{~d}$ of cocaine self-administration and $10-12 \mathrm{~d}$ of withdrawal (Fig. 3B). However, after bath application of ZIP, a low-frequency train of stimuli $(1 \mathrm{~Hz}, 10 \mathrm{~min})$ induced robust LTD in NAcc slices from cocaine-experienced mice (effect of cocaine, $F_{(1,32)}=11.72, p=0.002$; effect of $\operatorname{ZIP} F_{(1,32)}=6.86$, $p=0.01$; interaction, $F_{(1,32)}=3.85, p=0.05$; Sidak's multiplecomparisons test, cocaine ACSF vs cocaine ZIP, adjusted $p=$ $0.008 ; n=7-12$ slices (3-4 mice)/group; Figure $3 B-D$ ).

\section{Cocaine-induced disruption in mGluR5-dependent LTD is rescued by ZIP administration}

To determine whether ZIP's ability to rescue cocaine-induced deficits in LTD was specific to NMDAR-mediated plasticity, we examined mGluR5-dependent LTD within the NAcc of cocaine-experienced and yoked control mice. Previous work has shown disruptions in mGluR5-dependent LTD with the accumbens shell after experimenter-administered cocaine (Huang et al., 2011, 2015). We found that 10-14 d of cocaine self-administration followed by $10-14 \mathrm{~d}$ of withdrawal led to blunted DHPG induced LTD (effect of cocaine, $F_{(1,18)}=5.62$, $p=0.03$; effect of ZIP, $F_{(1,18)}=4.41, p=0.05$; interaction, $F_{(1,18)}$ $=6.34, p=0.02$; Sidak's multiple-comparisons test, control

\section{Cocaine-induced increase in AMPA/NMDA ratio is reversed} by ZIP administration

To determine whether ZIP is able to reverse other forms of cocaine-induced plasticity, we examined the AMPA/NMDA ratio within the NAcc of cocaine-experienced and yoked control mice. Previous work has shown increases in AMPA/NMDA ratio within the NAcc after cocaine self-administration (Moussawi et al., 2009). We found that $10-14 \mathrm{~d}$ of cocaine self-administration followed by $10-14 \mathrm{~d}$ of withdrawal led to an increase in the AMPA/NMDA ratio in the NAcc and this increase was reversed after bath application of ZIP (effect of cocaine, $F_{(1,62)}=10.93$, $p=0.001$; effect of ZIP, $F_{(1,62)}=2.85, p=0.096$; interaction, $F_{(1,62)}=5.44, p=0.02$; Sidak's multiple-comparisons test, cocaine vs cocaine + ZIP, adjusted $p=0.016 ; n=13-18$ cells from 5-6 mice per group; Fig. 5).

\section{Discussion}

The current studies demonstrate that a single intra-accumbal infusion of ZIP can block RI of cocaine seeking up to 1 week later. Consistent with what has been seen for the effects of ZIP on hippocampal dependent memory and long-term potentiation (Lee et al., 2013; Volk et al., 2013), the ability of ZIP to block cocaine seeking is $\mathrm{PKM} \zeta$ independent. However, the effects of ZIP on cocaine seeking do not generalize to natural rewards, as RI of sucrose seeking is not influenced by intra-accumbal infusion of ZIP. The ability of ZIP to disrupt cocaine-induced behavioral plasticity was accompanied by the ability to disrupt cocaine-induced synaptic plasticity. Our electrophysiological data revealed that ZIP rescues cocaine-induced deficits in NMDA-dependent and mGluR5-dependent LTD without affecting LTD in saline-yoked controls.

\section{Intra-accumbal administration of ZIP blunts RI of cocaine seeking in a persistent manner}

The present study shows that ZIP infusion into the NAc $24 \mathrm{~h}$ or even 1 week before testing can block RI of cocaine seeking, whereas the inactive form (SCR-ZIP) has no behavioral effect. To date, no other study has shown a compound that is able to block cocaine RI in such a long-lasting manner. In contrast to traditional pharmacological manipulations, ZIP is cleared from the brain before the $24 \mathrm{~h}$ test (Kwapis et al., 2012); therefore, its effect 
A

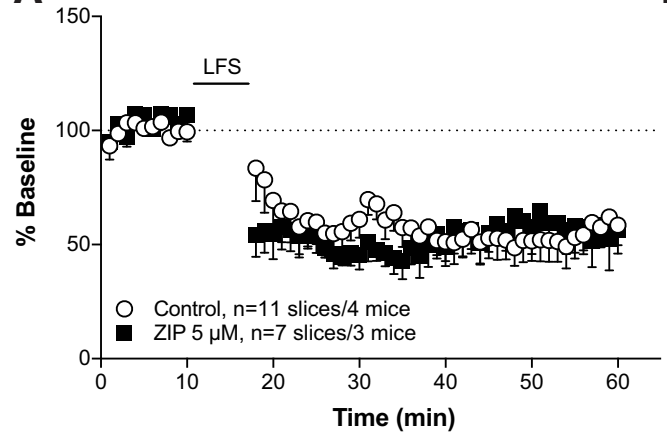

C

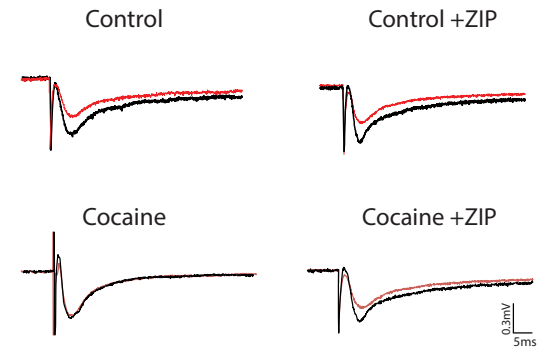

B

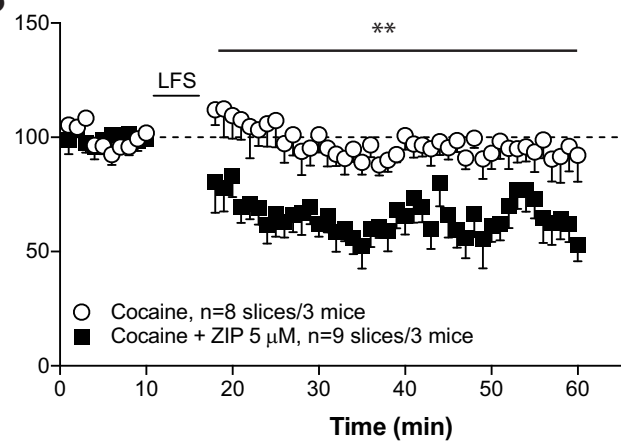

D

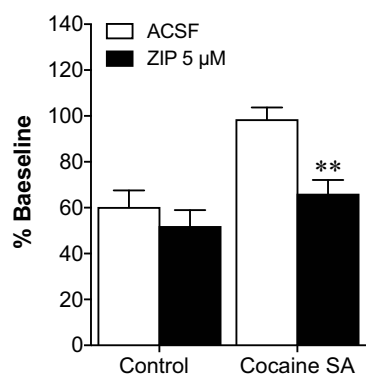

Figure 3. Bath application of ZIP rescues blunted NMDAR-LTD after cocaine self-administration. $A$, Yoked saline control mice exhibit reliable long-term depression after low-frequency stimulation (LFS) $(1 \mathrm{~Hz}, 10 \mathrm{~min})$ and this is not altered by bath application of ZIP. $\boldsymbol{B}$, Ten to $14 \mathrm{~d}$ of cocaine self-administration followed by $10-14 \mathrm{~d}$ of withdrawal leads to blunted NMDAR-LTD that is rescued by bath application of $5 \mu \mathrm{mZIP}$ (** $p<0.01$ main effect of bath infusion after LFS). C, Example traces demonstrate the rescue of LTD by ZIP in cocaine-experienced mice with baseline in black and post-LFS in red. $\boldsymbol{D}$, Change in fEPSP slope across the 30 min after LFS demonstrates robust LTD in control mice, blunted LTD after cocaine, and the rescue of LTD after bath application of ZIP in cocaine-experienced mice ${ }^{* *} p<0.01$ Sidak post hoc ACSF vs ZIP in cocaine-treated mice).

on RI does not depend upon continuous activity at its binding site. Previous studies have demonstrated long-lasting disruption of spatial memories after ZIP infusion into the hippocampus (Pastalkova et al., 2006; Serrano et al., 2008), taste memory after ZIP infusion in the insular cortex (Shema et al., 2007), fear memory after ZIP infusions in the amygdala (Serrano et al., 2008; Migues et al., 2010) and morphine, cocaine, and food conditioned place preference, after ZIP infusions into the NAc (Li et al., 2011).

However, the effect of ZIP in our experiments is not simply due to the erasure of reward-associated memories, as we do not see effects on sucrose-primed RI. At first, this may seem contradictory to previous findings demonstrating that ZIP is able to disrupt other forms of memory. However, these studies have administered ZIP into different brain regions that play a more general role in memory consolidation, including the hippocampus and the amygdala (Serrano et al., 2008; Madroñal et al., 2010; Migues et al., 2010; Kwapis et al., 2012; Evuarherhe et al., 2014). Previous studies examining infusions of ZIP into the NAc have found disruptions in conditioned place preference for high fat food (Li et al., 2011). Although it is possible these differences are due to the differ-
A

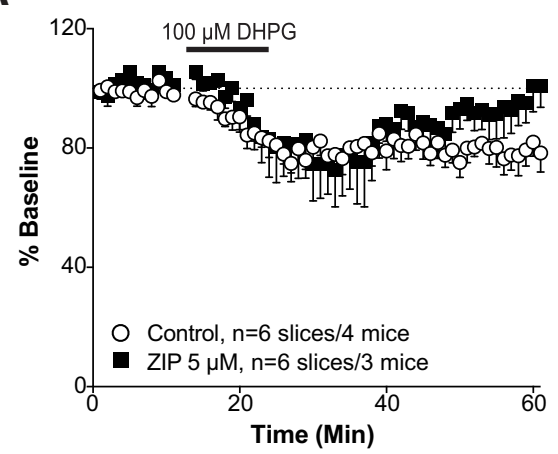

C

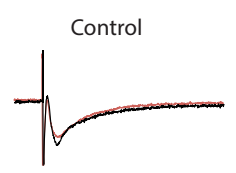

Control +ZIP

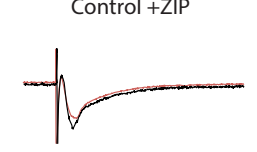

Cocaine

Cocaine + ZIP
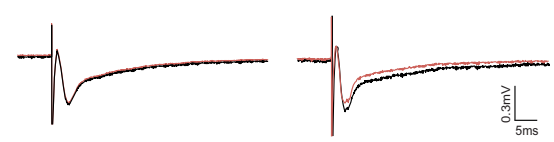

B

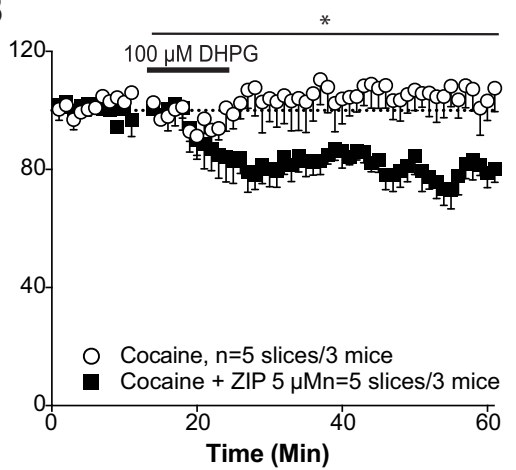

D

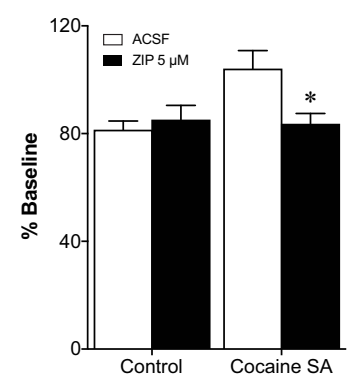

Figure 4. Bath application of ZIP rescues blunted mGluR5-LTD after cocaine self-administration. $A$, Yoked saline control mice exhibit reliable long-term depression after DHPG administration (100 $\mu \mathrm{M}, 10 \mathrm{~min})$ and this is not altered by bath application of ZIP. $\boldsymbol{B}$, Ten to $14 \mathrm{~d}$ of cocaine self-administration followed by $10-14 \mathrm{~d}$ of withdrawal leads to blunted mGluR5-LTD that is rescued by bath application of $5 \mu \mathrm{m} Z \mathrm{IP}\left({ }^{*} p<0.05\right.$ main effect of bath infusion after DHPG). C, Example traces demonstrate the rescue of mGluR5-LTD by ZIP in cocaine-experienced mice with baseline in black and post-DHPG in red. D, Change in fEPSP slope across the 30 min after DHPG demonstrates robust LTD in control mice, blunted LTD after cocaine, and the rescue of LTD after bath application of ZIP in cocaine-experienced mice ${ }^{*} p<0.05$ Sidak post hoc ACSF vs ZIP in cocaine-treated mice). 


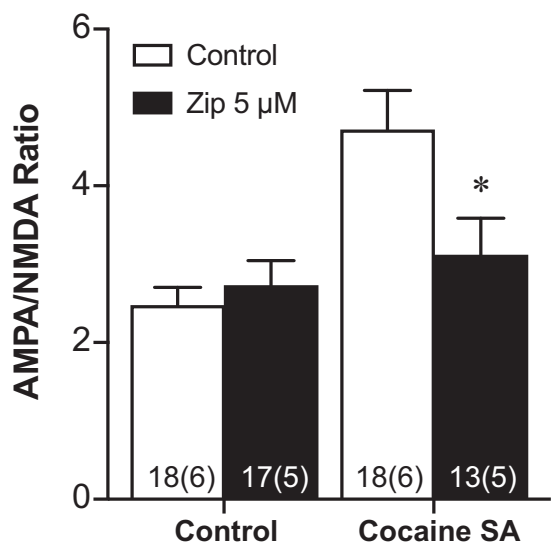

Figure 5. Bath application of ZIP reversed cocaine-induced increases in AMPA/NMDA ratio in the NAcc. Ten to $14 \mathrm{~d}$ of cocaine self-administration followed by $10-14 \mathrm{~d}$ of withdrawal leads to increased AMPA/NMDA ratio that is reversed by bath application of $5 \mu \mathrm{m}$ ZIP. Error bars indicate mean \pm SEM. Numbers in bars represent number of cells (number of animals); ${ }^{*} p<0.05$ Sidak post hoc cocaine vs cocaine + ZIP.

ent behavioral paradigms used to examine reward, if we examined RI of food seeking for a more highly palatable food we may find broader effects of intra-accumbal ZIP administration. However, the cocaine-specific effects seen in the current study may provide support for ZIP affecting glutamate plasticity in the NAc. ZIP has been shown to disrupt AMPAR trafficking (Yao et al., 2008; Migues et al., 2010; Yu et al., 2017), and manipulations of AMPAR trafficking in the NAc preferentially affect cocaineassociated behaviors leaving natural reward seeking intact (Anderson et al., 2008; Famous et al., 2008; Briand et al., 2014, 2016).

\section{Effect of ZIP on RI of cocaine seeking is independent of PKMzeta}

ZIP was initially designed to inhibit PKM $\zeta$ and therefore any actions of ZIP were attributed to its actions at PKM $\zeta$ (Yao et al., 2013). However, recent studies have called the specificity of ZIP into question, demonstrating that ZIP is able to disrupt LTP and memory in PKM $\zeta-\mathrm{KO}$ mice (Lee et al., 2013; Volk et al., 2013). Our results support a $\mathrm{PKM} \zeta$-independent mechanism for ZIP's actions on cocaine seeking. Others have suggested that the effect of ZIP in PKM $\zeta$-KO mice is due to compensatory actions of PKC ı/lambda (Tsokas et al., 2016). Although we do not see any upregulation of PKC ı/lambda (McGrath et al., 2018), we cannot rule this out as a potential mechanism. The current study does provide insight into the mechanism underlying the actions of ZIP as ZIP acts to rescue both NMDAR- and mGluR-mediated LTD, pointing to a mechanism common to these two forms of plasticity. Both forms of LTD ultimately lead to the removal of AMPA receptors from the synapse. Therefore, ZIP may be playing a role in this trafficking.

\section{ZIP application rescues-cocaine induced deficits in synaptic plasticity}

Here, we show that the bath application of ZIP leads to recovery of cocaine deficits in LTD within the NAc core. Furthermore, the ability of ZIP to rescue LTD is nonspecific in that we see recovery of both NMDA- and mGluR-mediated forms of LTD. The lack of LTD within the accumbens after cocaine suggests an inability to rescale synaptic transmission when contingencies are updated (Yin et al., 2009; Kasanetz et al., 2010). The ability of ZIP to restore the capacity for plasticity provides a mechanism by which ZIP may allow for the weakening of cue-induced craving. Con- sistent with this, optogenetic protocols that induce LTD within the accumbens block RI of cocaine seeking (Pascoli et al., 2014).

Both NMDA- and mGluR-mediated LTD require the internalization of the AMPA receptors (Kim et al., 2001; Snyder et al., 2001; Xiao et al., 2001). The trafficking of AMPA receptors after exposure to cocaine, is mediated, in part, by PKC (Famous et al., 2008). Furthermore, inhibition of PKC blocks cocaine-induced behavioral phenotypes, including RI of cocaine seeking (Steketee, 1993; Cervo et al., 1997; Schmidt et al., 2013). ZIP has been shown to inhibit multiple isoforms of PKC and interfere with the subcellular targeting of PKC (Bogard and Tavalin, 2015). Therefore, ZIP may be reversing cocaine-induced increases in PKCmediated insertion of AMPA receptors. This is supported by the current finding that ZIP reverses cocaine-induced increases in AMPA/NMDA ratio. ZIP is known to disrupt the interaction between atypical PKCs and their protein scaffold, p62, which in turn disrupts the interaction between GluA1 and GluA2 AMPA subunits and p62 (Tsai et al., 2015). As interactions between p62 and GluA1 can mediate AMPA receptor trafficking and subsequent log-term plasticity (Jiang et al., 2009), ZIP's ability to disrupt this interaction could mediate the behavioral and physiological changes we see in the current studies. Although it is not known how cocaine self-administration affects the interaction between atypical PKCs, p62, and AMPARs, morphine and methamphetamine increase the expression of p62, suggesting that drugs of abuse could recruit these AMPAR trafficking mechanisms (Lazzeri et al., 2018; Rodriguez et al., 2019).

The current electrophysiological studies used animals that underwent forced abstinence rather than active extinction of cocaine responding. Although both behavioral procedures are known to disrupt LTD (Moussawi et al., 2009; Briand et al., 2014), extinction does lead to alterations in glutamate plasticity that are not present after forced abstinence. Abstinence leads to an increase in GluA2 expression in the nonsynaptic fraction, potentially suggesting differences in AMPAR trafficking between the two protocols (Knackstedt et al., 2010). However, as there are no differences in AMPAR subunit expression in the synaptic fraction these differences may not influence the forms of plasticity examined in the current studies. In contrast, there are clear differences in mGluR5 surface expression, as well as proteins involved in mGluR5 trafficking, after extinction that are not present after abstinence (Knackstedt et al., 2010). This would suggest that DHPG-induced LTD would also be disrupted after extinction and future work could confirm that ZIP would reverse this plasticity to the same extent as it does in the current study.

At high concentrations, ZIP has been shown to be toxic to cells and lead to cell death in culture (Sadeh et al., 2015). Although a lesion of the NAc could lead to the effects we see on RI behavior, we did not see any histological evidence for this and the specificity of our effect to cocaine versus sucrose suggests this is not the case. Furthermore, we did not see any effect of ZIP on LTD in drugnaive animals, suggesting that the effects of ZIP are more specific than simply generalized toxicity.

\section{Conclusion}

The current study establishes that intra-accumbal ZIP administration blocks cue-induced cocaine seeking in a persistent manner while not affecting sucrose seeking. Furthermore, ZIP can rescue two forms of LTD that are disrupted by cocaine self-administration. We suggest that the ability of ZIP to restore the capacity to weaken synaptic input may underlie its behavioral effects. 


\section{References}

Anderson SM, Famous KR, Sadri-Vakili G, Kumaresan V, Schmidt HD, Bass CE, Terwilliger EF, Cha JH, Pierce RC (2008) CaMKII: a biochemical bridge linking accumbens dopamine and glutamate systems in cocaine seeking. Nat Neurosci 11:344-353.

Bogard AS, Tavalin SJ (2015) Protein kinase C (PKC)zeta pseudosubstrate inhibitor peptide promiscuously binds PKC family isoforms and disrupts conventional PKC targeting and translocation. Mol Pharmacol 88:728735.

Briand LA, Kimmey BA, Ortinski PI, Huganir RL, Pierce RC (2014) Disruption of glutamate receptor-interacting protein in nucleus accumbens enhances vulnerability to cocaine relapse. Neuropsychopharmacology 39: 759-769.

Briand LA, Deutschmann AU, Ellis AS, Fosnocht AQ (2016) Disrupting GluA2 phosphorylation potentiates reinstatement of cocaine seeking. Neuropharmacology 111:231-241.

Cervo L, Mukherjee S, Bertaglia A, Samanin R (1997) Protein kinases A and $\mathrm{C}$ are involved in the mechanisms underlying consolidation of cocaine place conditioning. Brain Res 775:30-36.

Childress AR, Hole AV, Ehrman RN, Robbins SJ, McLellan AT, O’Brien CP (1993) Cue reactivity and cue reactivity interventions in drug dependence. NIDA Res Monogr 137:73-95.

Cornish JL, Duffy P, Kalivas PW (1999) A role for nucleus accumbens glutamate transmission in the relapse to cocaine-seeking behavior. Neuroscience 93:1359-1367.

Dackis CA, O'Brien CP (2001) Cocaine dependence: a disease of the brain's reward centers. J Subst Abuse Treat 21:111-117.

Everitt BJ, Giuliano C, Belin D (2018) Addictive behaviour in experimental animals: prospects for translation. Philos Trans R Soc Lond B Biol Sci. Advance online publication. Retrieved March 19, 2018. doi: 10.1098/ rstb.2017.0027

Evuarherhe O, Barker GR, Savalli G, Warburton EC, Brown MW (2014) Early memory formation disrupted by atypical PKC inhibitor ZIP in the medial prefrontal cortex but not hippocampus. Hippocampus 24:934942.

Famous KR, Kumaresan V, Sadri-Vakili G, Schmidt HD, Mierke DF, Cha JH, Pierce RC (2008) Phosphorylation-dependent trafficking of GluR2containing AMPA receptors in the nucleus accumbens plays a critical role in the reinstatement of cocaine seeking. J Neurosci 28:11061-11070.

Heinsbroek JA, Neuhofer DN, Griffin WC 3rd, Siegel GS, Bobadilla AC, Kupchik YM, Kalivas PW (2017) Loss of plasticity in the D2-accumbens pallidal pathway promotes cocaine seeking. J Neurosci 37:757-767.

Ho SY, Chen CH, Liu TH, Chang HF, Liou JC (2012) Protein kinase mzeta is necessary for cocaine-induced synaptic potentiation in the ventral tegmental area. Biol Psychiatry 71:706-713.

Howell KK, Monk BR, Carmack SA, Mrowczynski OD, Clark RE, Anagnostaras SG (2014) Inhibition of PKC disrupts addiction-related memory. Front Behav Neurosci 8:70.

Hrabetova S, Sacktor TC (1996) Bidirectional regulation of protein kinase $\mathrm{M}$ zeta in the maintenance of long-term potentiation and long-term depression. J Neurosci 16:5324-5333.

Huang CC, Yeh CM, Wu MY, Chang AY, Chan JY, Chan SH, Hsu KS (2011) Cocaine withdrawal impairs metabotropic glutamate receptor-dependent long-term depression in the nucleus accumbens. J Neurosci 31:41944203.

Huang CC, Liang YC, Lee CC, Hsu KS (2015) Cocaine withdrawal impairs mGluR5-dependent long-term depression in nucleus accumbens shell neurons of both direct and indirect pathways. Mol Neurobiol 52:12231233.

Jiang J, Parameshwaran K, Seibenhener ML, Kang MG, Suppiramaniam V, Huganir RL, Diaz-Meco MT, Wooten MW (2009) AMPA receptor trafficking and synaptic plasticity require SQSTM1/p62. Hippocampus 19: 392-406.

Kalivas PW, McFarland K (2003) Brain circuitry and the reinstatement of cocaine-seeking behavior. Psychopharmacology (Berl) 168:44-56.

Kasanetz F, Deroche-Gamonet V, Berson N, Balado E, Lafourcade M, Manzoni O, Piazza PV (2010) Transition to addiction is associated with a persistent impairment in synaptic plasticity. Science 328:1709-1712.

Kim CH, Chung HJ, Lee HK, Huganir RL (2001) Interaction of the AMPA receptor subunit GluR2/3 with PDZ domains regulates hippocampal long-term depression. Proc Natl Acad Sci U S A 98:11725-11730.

Knackstedt LA, Moussawi K, Lalumiere R, Schwendt M, Klugmann M, Kali- vas PW (2010) Extinction training after cocaine self-administration induces glutamatergic plasticity to inhibit cocaine seeking. J Neurosci 30:7984-7992.

Knackstedt LA, Trantham-Davidson HL, Schwendt M (2014) The role of ventral and dorsal striatum mGluR5 in relapse to cocaine-seeking and extinction learning. Addict Biol 19:87-101.

Kwapis JL, Jarome TJ, Gilmartin MR, Helmstetter FJ (2012) Intra-amygdala infusion of the protein kinase mzeta inhibitor ZIP disrupts foreground context fear memory. Neurobiol Learn Mem 98:148-153.

LaCrosse AL, O'Donovan SM, Sepulveda-Orengo MT, McCullumsmith RE, Reissner KJ, Schwendt M, Knackstedt LA (2017) Contrasting the role of $\mathrm{xCT}$ and GLT-1 upregulation in the ability of ceftriaxone to attenuate the cue-induced reinstatement of cocaine seeking and normalize AMPA receptor subunit expression. J Neurosci 37:5809-5821.

Lazzeri G, Biagioni F, Fulceri F, Busceti CL, Scavuzzo MC, Ippolito C, Salvetti A, Lenzi P, Fornai F (2018) mTOR modulates methamphetamineinduced toxicity through cell clearing systems. Oxid Med Cell Longev 2018:6124745.

Lee AM, Kanter BR, Wang D, Lim JP, Zou ME, Qiu C, McMahon T, Dadgar J, Fischbach-Weiss SC, Messing RO (2013) Prkcz null mice show normal learning and memory. Nature 493:416-419.

Li YQ, Xue YX, He YY, Li FQ, Xue LF, Xu CM, Sacktor TC, Shaham Y, Lu L (2011) Inhibition of PKM\{zeta\} in nucleus accumbens core abolishes long-term drug reward memory. J Neurosci 31:5436-5446.

Madroñal N, Gruart A, Sacktor TC, Delgado-García JM (2010) PKMzeta inhibition reverses learning-induced increases in hippocampal synaptic strength and memory during trace eyeblink conditioning. PLoS One 5:e10400.

Mahler SV, Smith RJ, Aston-Jones G (2013) Interactions between VTA orexin and glutamate in cue-induced reinstatement of cocaine seeking in rats. Psychopharmacology (Berl) 226:687-698.

Mahler SV, Hensley-Simon M, Tahsili-Fahadan P, LaLumiere RT, Thomas C, Fallon RV, Kalivas PW, Aston-Jones G (2014) Modafinil attenuates reinstatement of cocaine seeking: role for cystine-glutamate exchange and metabotropic glutamate receptors. Addict Biol 19:49-60.

Manuszak M, Harding W, Gadhiya S, Ranaldi R (2018) (-)-stepholidine reduces cue-induced reinstatement of cocaine seeking and cocaine selfadministration in rats. Drug Alcohol Depend 189:49-54.

Martin M, Chen BT, Hopf FW, Bowers MS, Bonci A (2006) Cocaine selfadministration selectively abolishes LTD in the core of the nucleus accumbens. Nat Neurosci 9:868-869.

McFarland K, Kalivas PW (2001) The circuitry mediating cocaine-induced reinstatement of drug-seeking behavior. J Neurosci 21:8655-8663.

McFarland K, Davidge SB, Lapish CC, Kalivas PW (2004) Limbic and motor circuitry underlying footshock-induced reinstatement of cocaine-seeking behavior. J Neurosci 24:1551-1560.

McGrath AG, Lenz JD, Briand LA (2018) PKMzeta in the nucleus accumbens acts to dampen cocaine seeking. Neuropsychopharmacology 43: $2390-2398$

Migues PV, Hardt O, Wu DC, Gamache K, Sacktor TC, Wang YT, Nader K (2010) PKMzeta maintains memories by regulating GluR2-dependent AMPA receptor trafficking. Nat Neurosci 13:630-634.

Moussawi K, Pacchioni A, Moran M, Olive MF, Gass JT, Lavin A, Kalivas PW (2009) N-acetylcysteine reverses cocaine-induced metaplasticity. Nat Neurosci 12:182-189.

Pascoli V, Terrier J, Espallergues J, Valjent E, O'Connor EC, Lüscher C (2014) Contrasting forms of cocaine-evoked plasticity control components of relapse. Nature 509:459-464.

Pastalkova E, Serrano P, Pinkhasova D, Wallace E, Fenton AA, Sacktor TC (2006) Storage of spatial information by the maintenance mechanism of LTP. Science 313:1141-1144.

Reissner KJ, Gipson CD, Tran PK, Knackstedt LA, Scofield MD, Kalivas PW (2015) Glutamate transporter GLT-1 mediates N-acetylcysteine inhibition of cocaine reinstatement. Addict Biol 20:316-323.

Rodriguez M, Lapierre J, Ojha CR, Pawitwar S, Karuppan MKM, Kashanchi F, El-Hage N (2019) Morphine counteracts the antiviral effect of antiretroviral drugs and causes upregulation of p62/SQSTM1 and histonemodifying enzymes in HIV-infected astrocytes. J Neurovirol 25:263-274.

Sacktor TC (2011) How does PKMzeta maintain long-term memory? Nat Rev Neurosci 12:9-15.

Sadeh N, Verbitsky S, Dudai Y, Segal M (2015) Zeta inhibitory peptide, a 
candidate inhibitor of protein kinase $\mathrm{M} \zeta$, is excitotoxic to cultured hippocampal neurons. J Neurosci 35:12404-12411.

Schmidt HD, Schassburger RL, Guercio LA, Pierce RC (2013) Stimulation of mGluR 5 in the accumbens shell promotes cocaine seeking by activating PKC gamma. J Neurosci 33:14160-14169.

Serrano P, Friedman EL, Kenney J, Taubenfeld SM, Zimmerman JM, Hanna J, Alberini C, Kelley AE, Maren S, Rudy JW, Yin JC, Sacktor TC, Fenton AA (2008) PKMzeta maintains spatial, instrumental, and classically conditioned long-term memories. PLoS Biol 6:2698-2706.

Shabashov D, Shohami E, Yaka R (2012) Inactivation of PKMzeta in the NAc shell abolished cocaine-conditioned reward. J Mol Neurosci 47:546-553.

Shema R, Sacktor TC, Dudai Y (2007) Rapid erasure of long-term memory associations in the cortex by an inhibitor of PKM zeta. Science 317: 951-953.

Snyder EM, Philpot BD, Huber KM, Dong X, Fallon JR, Bear MF (2001) Internalization of ionotropic glutamate receptors in response to mGluR activation. Nat Neurosci 4:1079-1085.

Steketee JD (1993) Injection of the protein kinase inhibitor H7 into the A10 dopamine region blocks the acute responses to cocaine: behavioral and in vivo microdialysis studies. Neuropharmacology 32:1289-1297.

Tsai LC, Xie L, Dore K, Xie L, Del Rio JC, King CC, Martinez-Ariza G, Hulme C, Malinow R, Bourne PE, Newton AC (2015) Zeta inhibitory peptide disrupts electrostatic interactions that maintain atypical protein kinase $\mathrm{C}$ in its active conformation on the scaffold p62. J Biol Chem 290: 21845-21856.

Tsokas P, Hsieh C, Yao Y, Lesburguères E, Wallace EJC, Tcherepanov A, Jothianandan D, Hartley BR, Pan L, Rivard B, Farese RV, Sajan MP, Bergold PJ, Hernández AI, Cottrell JE, Shouval HZ, Fenton AA, Sacktor TC (2016) Compensation for PKMzeta in long-term potentiation and spatial long-term memory in mutant mice. Elife 5:e14846.
Vaquer-Alicea ADC, Vázquez-Torres R, Devarie-Hornedo M, VicentyPadilla JC, Santos-Vera B, María-Ríos C, Vélez-Hernández ME, Sacktor T, Jiménez-Rivera CA (2018) aPKC-mediated persistent increase in AMPA/NMDA ratio in the VTA participates in the neuroadaptive signal necessary to induce NAc synaptic plasticity after cocaine administration. Neuroscience 392:129-140.

Volk LJ, Bachman JL, Johnson R, Yu Y, Huganir RL (2013) PKM-zeta is not required for hippocampal synaptic plasticity, learning and memory. Nature 493:420-423.

Xiao MY, Zhou Q, Nicoll RA (2001) Metabotropic glutamate receptor activation causes a rapid redistribution of AMPA receptors. Neuropharmacology 41:664-671.

Yao Y, Kelly MT, Sajikumar S, Serrano P, Tian D, Bergold PJ, Frey JU, Sacktor TC (2008) PKM zeta maintains late long-term potentiation by $\mathrm{N}$-ethylmaleimide-sensitive factor/GluR2-dependent trafficking of postsynaptic AMPA receptors. J Neurosci 28:7820-7827.

Yao Y, Shao C, Jothianandan D, Tcherepanov A, Shouval H, Sacktor TC (2013) Matching biochemical and functional efficacies confirm ZIP as a potent competitive inhibitor of PKMzeta in neurons. Neuropharmacology 64:37-44.

Yin HH, Mulcare SP, Hilário MR, Clouse E, Holloway T, Davis MI, Hansson AC, Lovinger DM, Costa RM (2009) Dynamic reorganization of striatal circuits during the acquisition and consolidation of a skill. Nat Neurosci 12:333-341.

Yu NK, Uhm H, Shim J, Choi JH, Bae S, Sacktor TC, Hohng S, Kaang BK (2017) Increased PKMzeta activity impedes lateral movement of GluA2containing AMPA receptors. Mol Brain 10:56.

Zhang Y, Zong W, Zhang L, Ma Y, Wang J (2016) Protein kinase M zeta and the maintenance of long-term memory. Neurochem Int 99:215-220. 